\title{
PENERAPAN UKURAN KETEPATAN NILAI RAMALAN DATA DERET WAKTU DALAM SELEKSI MODEL PERAMALAN VOLUME PENJUALAN PT SATRIAMANDIRI CITRAMULIA
}

\author{
Iwa Sungkawa; Ries Tri Megasari \\ Mathematics \& Statistics Department, School of Computer Science, Binus University \\ Jl. K.H. Syahdan No. 9, Palmerah, Jakarta Barat 11480 \\ iwasungkawa@yahoo.com
}

\begin{abstract}
Forecasting is performed due to the complexity and uncertainty faced by a decision maker. This article discusses the selection of an appropriate forecasting model with time series data available. An appropriate forecasting model is required to estimate systematically about what is most likely to occur in the future based on past data series, so that errors (the differences between what actually happens and the results of the estimation) can be minimized. A gauge is required to detect the required the value of forecast accuracy. In this paper ways of forecasting accuracy of detection are discussed using the mean square error (MSE) and the mean absolute percentage error (MAPE). The forecasting method uses Moving Average, Exponential Smoothing, and Winters method. With the three methods forecast value is determined and the smallest value of MSE and Mape is selected. The results of data analysis showed that the Exponential Smoothing is considered an appropriate method to forecast the sales volume of PT Satriamandiri Citramulia because it produces the smallest value of MSE and Mape.
\end{abstract}

Keywords: forecast, time series data, Moving Average, Exponential Smoothing, Winters, means square error (MSE), mean absolute percentage error (MAPE)

\begin{abstract}
ABSTRAK
Peramalan dilakukan karena adanya kompleksitas dan ketidakpastian yang dihadapi oleh si pembuat keputusan. Artikel ini membahas pemilihan model peramalan yang sesuai dengan data deret waktu yang ada. Suatu proses untuk memperkirakan secara sistematik tentang apa yang paling mungkin terjadi di masa depan berdasarkan data series masa lalu dan sekarang memerlukan model peramalan yang tepat/sesuai, agar kekeliruannya (selisih antara apa yang terjadi dengan hasil perkiraan) dapat diperkecil. Untuk mendapatkan metode yang tepat diperlukan alat ukur untuk mendeteksi ketepatan nilai ramalan. Dalam tulisan ini dibahas cara deteksi ketepatan peramalan dengan mean square error (MSE) dan mean absolute percentage error (MAPE). Peramalan menggunakan metode Moving Average, Exponential Smoothing, dan Winters. Dengan ketiga metode di atas ditentukan nilai ramalan dan dipilih nilai MSE dan MAPE terkecil. Hasil analisis data menunjukkan bahwa Exponential Smoothing dianggap metode yang tepat untuk meramalkan volume penjualan PT Satriamandiri Citramulia karena menghasilkan nilai MSE dan MAPE terkecil.
\end{abstract}

Kata kunci: ramalan, data deret waktu, Moving Average, Exponential Smoothing, Winters, means square error (MSE), mean absolute percentage error (MAPE) 


\section{PENDAHULUAN}

Persaingan bisnis yang semakin ketat, mengharuskan para pelaku bisnis untuk melihat peluang pasar yang ada dalam menyusun strategi dan rencana yang akan dilaksanakan agar dapat meningkatkan penjualan untuk memperoleh keuntungan yang maksimal. Kunci kesuksesan dalam rangka meningkatkan penjualan para pelaku bisnis perlu memperhatikan selera dan kebutuhan konsumen serta selalu melayani/memenuhi permintaan konsumen. Yang perlu dilakukan oleh pelaku bisnis sebagai pengambil keputusan dalam suatu perusahaan adalah mengatur dan meningkatkan volume penjualan secara berkala.

Dalam meningkatkan penjualannya di masa yang akan datang maka pengambilan keputusan berkaitan erat dengan peramalan (forecasting) (Assauri, 1984). Peramalan dilakukan karena adanya kompleksitas dan ketidakpastian yang dihadapi oleh si pembuat keputusan berkenaan dengan masa depan usaha yang dijalani. Peramalan yang dilakukan umumnya didasarkan pada data masa lalu yang kemudian dianalisis dengan menggunakan metode tertentu. Data masa lalu dikumpulkan, dipelajari, dianalisis dan dihubungkan dengan berjalannya waktu. Ramalan yang baik adalah ramalan yang mendekati kenyataan. Hasil suatu ramalan tidak selalu dapat dipastikan kebenarannya dalam hitungan $100 \%$ mutlak, tetapi hal tersebut tidak berarti bahwa peramalan yang telah dilakukan menjadi percuma.

Dalam kesempatan ini akan dilakukan kajian terhadap volume penjualan PT.Satriamandiri Citramulia yang merupakan distributor baja lapis seng merk lokfom. Peramalan yang dilakukan dengan menggunakan tiga metode yang ada dalam analisis deret waktu, yaitu metode moving anerage (rata-rata bergerak), Exponential Smoothing (pemulusan eksponensial), dan metode Winters (musiman). Dengan menggunakan tiga metode tersebut akan dipilih model peramalan mana yang dianggap cocok untuk meramalkan volume penjualan PT.Satriamandiri Citramulia.

Tujuan dari penulisan ini adalah melakukan deteksi terhadap ketepatan hasil peramalan dengan menggunakan tiga ukuran seperti mean square error (MSE), mean absolute percentage error (MAPE), serta untuk melihat keragaman dari galat/error dari tiga metode peramalan yang digunakan ditelaah dengan statistik durbin watson (D-W).

Dengan mengetahui model/metode yang cocok untuk meramalkan penjualan perusahaan diwaktu yang akan datang tentunya akan diperoleh hasil ramalan yang terandalkan, sehingga akan memudahkan dalam mengatur produksi atau stok sejenis barang. Serta dapat menentukan kapan waktu yang tepat untuk memproduksi barang yang dijual oleh perusahaan tersebut.

Penjualan merupakan salah satu aspek yang penting bagi PT. Satriamandiri Citramulia. Peramalan volume penjualan ini dilakukan untuk mengetahui berapa banyak penjualan yang dilakukan sehingga dapat meramalkan penjualan perusahaan pada bulan berikutnya. Dalam tulisan ini digunakan data yang bersumber dari Megasari (2010) tentang volume penjualan PT. Satriamandiri Citramulia selama bulan September 2006 sampai dengan September 2010.

\section{METODE}

Berdasarkan kerangka teori dalam analisis deret waktu, diketahui bahwa metode Winters memilki keunnggulan dalam meramalkan pola data yang memiliki pola trend dan musiman sehingga mampu memperkirakan penjualan pada tahun-tahun berikutnya dengan baik. Namun, metode Winters sangat bergantung pada taksiran peramalan awal. Metode Exponential Smoothing memiliki 
keunggulan dalam mengurangi masalah penyimpanan data. Sedangkan, metode Moving Average melakukan perhitungan terhadap nilai data baru dan data lama dihapus tetapi metode ini memilki kelemahan yaitu semua memiliki bobot yang sama. Selanjutnya, untuk mengetahui metode mana yang paling baik dari ketiga metode tersebut dalam meramalkan volume penjualan yang akan datang, dapat dilakukan deteksi terhadap hasil peramalan dengan menghitung nilai MSE dan MAPE, yang merupakan kajian dengan menguji error (kekeliruan) dari masing-masing metode peramalan yang digunakan. Metode peramalan dengan nilai MSE dan MAPE terkecil merupakan metode yang terbaik dan akan digunakan untuk melakukan kajian atau analisis volume penjualan.

\section{Moving Average}

Moving average adalah suatu metode peramalan umum dan mudah untuk menggunakan alatalat yang tersedia untuk analisis teknis. Moving average menyediakan metode sederhana untuk pemulusan data masa lalu. Metode ini berguna untuk peramalan ketika tidak terjadi tren. Jika terdapat tren, gunakan estimasi berbeda untuk mempertimbangkannya. Hal ini disebut dengan "bergerak" karena sebagai data baru yang tersedia, data yang tertua tidak digunakan lagi (Makridakis et all, 1999).

Tujuan utama penggunaan rata-rata bergerak adalah untuk menghilangkan atau mengurangi acakan dalam deret waktu. Teknik rata-rata bergerak dalam deret waktu terdiri dari pengambilan suatu kumpulan nilai-nilai yang diobservasi, mendapatkan rata-rata dari nilai ini, dan kemudian menggunakan nilai rata-rata tersebut sebagai ramalan untuk periode yang akan datang. (Assauri,1984, p.23)

Peramalan dengan teknik Moving Average melakukan perhitungan terhadap nilai data yang paling baru sedangkan data yang lama akan dihapus. Nilai rata-rata dihitung berdasarkan jumlah data yang angka rata-ratanya bergeraknya ditentukan dari harga 1 sampai $N$ data yang dimiliki.

Moving average dihitung dengan menggunakan rumus sebagai berikut:

$$
F_{i=1}=\frac{1}{N} \sum_{i=t-N+1}^{t} X_{i}
$$

dimana $t$ adalah nilai yang paling akhir dan $t+1$ adalah periode berikutnya, untuk periode mana suatu ramalan dibuat.

$E_{t+1}=$ ramalan untuk periode yang berikut, $t+1$

$X_{\mathrm{t}, \mathrm{t}-1, \mathrm{t}-2}=$ nilai observasi/sebenarnya dari variabel itu pada periode $t, t-1, t-2, \ldots .$.

$N=$ Jumlah observasi yang digunakan dalam menghitung rata-rata bergerak

Dalam model Moving Average dapat dilihat bahwa semua data observasi memiliki bobot yang sama yang membentuk rata-ratanya. Padahal data observasi terbaru seharusnya memiliki bobot yang lebih besar dibandingkan dengan data observasi di masa lalu. Hal ini dipandang sebagai kelemahan dalam metode Moving Average.

\section{Exponential Smoothing}

Exponential smoothing adalah metode yang menunjukkan pembobotan menurun secara eksponensial terhadap nilai pengamatan yang lebih tua. Terdapat satu atau lebih parameter penulisan yang ditentukan secara eksplisit, dan hasil pilhan ini menetukan bobot yang dikenakan pada nilai observasi. (Makridakis et all, 1999, p.78).

Beberapa keuntungan dari penggunaan metode Exponential Smoothing adalah banyak mengurangi masalah penyimpanan data, sehingga tidak perlu lagi menyimpan semua data historis atau sebagian; hanya pengamatan terakhir, ramalan terakhir, dan suatu nilai konstanta yang harus disimpan. (Makridakis et all, 1999, p.103-104). 
Metode ini dipergunakan secara luas didalam peramalan karena sederhana, efisien didalam perhitungan ramalan, mudah disesuaikan dengan perubahan data, dam ketelitian metode ini cukup besar

Metode ini digunakan untuk melakukan pemulusan terhadap suatu deret berkala dengan membuat rata-rata tertimbang dari sederetan data yang lalu. Metode ini sangat efektif untuk peramalan jangka pendek dan tidak membutuhkan banyak data.

Metode Exponential Smoothing cocok untuk data yang bergerak acak ke atas dan ke bawah secara terus menerus berarti tidak ada tren maupun musiman.

$$
Y_{t+1}^{t}=\propto Y_{t}+(1-\infty) Y_{t}
$$

dimana $0<\ll<1$ adalah faktor pemulusan. Semakin kecil nilai alpha, semakin mulus suatu data. Dengan nilai $\mathrm{Y}_{(1)}$ untuk inisial nilai ramalan didekati dengan nilai rata-rata $(\bar{Y})$ atau

$$
Y_{t}=Y_{(t-1)}^{\prime}+\alpha\left(Y_{(t-1)}-Y_{(t-1)}^{\prime}\right)
$$

\section{Winters}

Apabila suatu data time series diketahui adanya pola musiman di samping pola data trend, metode Winters merupakan satu-satunya metode pendekatan pemulusan yang banyak digunakan.

Menurut Makridakis, Wheelright, dan McGee (1999. P.122-127), metode Winters merupakan metode yang dapat menangani faktor musiman dan tren secara langsung. Metode ini didasarkan atas tiga persamaan pemulusan dengan tiga paramater, yaitu satu untuk unsur stasioner, satu untuk trend, dan satu untuk musiman.

Keuntungan dari metode Winters adalah memiliki kemampuan yang sangat baik dalam meramalkan data yang memiliki pola trend dan musiman. Metode Winters digunakan untuk meramalkan suatu hasil yang disesuaikan dengan variasi trend dan musiman yang tidak dapat diatasi oleh metode Moving Average dan metode Exponential Smoothing. Metode Winters menyediakan tiga parameter untuk memperhalus nilai, yaitu base, trend, dan musiman.

Persamaan dasar untuk metode Winters adalah sebagai berikut:

Pemulusan keseluruhan.

$$
S_{t}=\alpha \frac{X_{t}}{I_{t-L}}+(1-\alpha)\left(S_{t-1}+b_{t-1}\right)
$$

Pemulusan trend

$$
b_{t}=\gamma\left(S_{t}-S_{t-1}\right)+(1-\gamma) b_{t-1}
$$

Pemulusan musiman

$$
I_{t}=\beta \frac{X_{t}}{S_{t}}+(1-\beta) I_{t-L}
$$

Ramalan

$$
F_{t+m}=\left(S_{t}+b_{t} m\right) I_{t-L+m}
$$


dimana $L$ adalah panjang musiman (misal: umlah bulan atau kuartal dalam suatu tahun), $b$ adalah komponen trend, $I$ adalah faktor penyesuaian musiman, dan $F_{t+m}$ adalah ramalan untuk $m$ periode ke muka.

Persamaan 6 dapat dibandingkan dengan indeks musiman yang merupakan rasio antara nilai sekarang dari deret data, $X_{t}$, dibagi dengan nilai pemulusan tunggal yang sekarang untuk deret data tersebut, $S_{t}$. Jika $X_{t}$ lebih besar daripada $S_{t}$, rasio tersebut akan lebih besar daripada 1. Sedangkan jika $X_{t}$ lebih kecil daripada $S_{t}$, rasio tersebut akan lebih kecil daripada 1. Untuk memahami metode ini kita perlu menyadari bahwa $S_{t}$ merupakan nilai pemulusan (rata-rata) dari deret data yang tidak termasuk unsur musiman. Juga perlu diingat bahwa $X_{t}$ mencakup adanya kerandoman dalam deret data. Untuk menghaluskan keacakan ini, persamaan 6 membobot faktor musiman yang dihitung paling akhir dengan $\beta$ dan angka musiman paling akhir pada musiman yang sama dengan (1- $\beta$ ). (Faktor musiman sebelum ini dihitung pada periode $t-L$, karena $L$ adalah panjang musiman).

Persamaan 5 tepat sama dengan persamaan dari Holt untuk pemulusan trend, yaitu

$$
b_{t}=\gamma\left(S_{t}-S_{t-1}\right)+(1-\gamma) b_{t-1}
$$

Persamaan 4 berbeda sedikit dari persamaan

$$
S_{t}=\alpha X_{t}+(1-\alpha)\left(S_{t-1}+b_{t-1}\right)
$$

dari Holt, dimana unsur pertamanya dibagi dengan angka musiman $I_{t-L}$. Hal ini dilakukan untuk menghilangkan musiman (mengeliminasi fluktuasi musiman dari) $X_{t}$.

Penyesuian ini dapat digambarkan dengan memperhatikan kasus dimana $I_{t-L}$ lebih besar daripada 1 , yang terjadi pada saat nilai periode $t-L$ lebih besar daripada rata-rata dalam musimannya. Membagi $X_{t}$ dengan bilangan yang lebih besar daripada 1 ini menghasilkan suatu nilai yang lebih kecil daripada nilai semula. Persentase penurunan ini sama dengan banyaknya unsur musiman pada periode $t-L$ yang lebih besar daripada nilai rata-rata. Penyesuaian yang sebaliknya terjadi bilamana angka musiman lebih kecil daripada 1 . Nilai $I_{t-L}$ digunakan dalam perhitungan ini karena $I_{t}$ tidak dapat dihitung sebelum $S_{t}$ diketahui dari persamaan pemulusan keseluruhan.

Metode Winters juga memiliki kelemahan, kelemahan utama yang menghambat pemakaiannya secara luas yaitu membutuhkan tiga parameter pemulusan (alpha, beta, gamma) yang dapat bernilai antara 0 dan 1, sehingga banyak kombinasi yang harus dicobakan sebelum nilai parameter yang optimal ditentukan. Metode alternatif yang dapat mengurangi keraguan tentang nilai optimal adalah menacari nilai taksiran awal yang lebih baik, lalu menetapkan nilai yang kecil untuk ketiga parameter pemulusan (sekitar 0,1 sampai dengan 0,3). Nilai 0,1 membuat ramalan bersifat terlalu berhati-hati, sedangkan nilai 0,3 memberikan sistem yang lebih responsif. Karena adanya himpunan pilihan nilai yang dipersempit ini, metode ini biasanya dipandang sebagai metode yang lebih mudah digunakan (Makridakis et al.,1999, p.137).

\section{Ukuran Ketepatan Nilai Peramalan}

Dalam semua situasi peramalan mengandung derajat ketidakpastian. Kita mengenali fakta ini dengan memasukkan unsur kesalahan (error) dalam perumusan sebuah peramalan deret waktu. Sumber penyimpangan dalam peramalan bukan hanya disebabkan oleh unsur error, tetapi ketidakmampuan suatu model peramalan mengenali unsur yang lain dalam deret data juga mempengaruhi besarnya penyimpangan dalam peramalan. Jadi besarnya penyimpangan hasil peramalan bisa disebabkan oleh besarnya faktor yang tidak diduga (outliers) dimana tidak ada metode peramalan yang mampu menghasilkan peramalan yang akurat, atau bisa juga disebabkan metode peramalan yang digunakan tidak dapat memprediksi dengan tepat komponen trend, komponen 
musiman, atau komponen siklus yang mungkin terdapat dalam deret data, yang berarti metode yang digunakan tidak tepat (Bowerman dan O’Connell, 1987, p.12).

Jika $X i$ merupakan data aktual untuk periode $i$ dan $F_{i}$ merupakan ramalan (atau nilai kecocokan/fitted value) untuk periode yang sama, kesalahan didefinisikan sebagai

$$
\mathrm{e}_{\mathrm{i}}=\mathrm{X}_{\mathrm{i}}-\mathrm{F}_{\mathrm{i}}
$$

Jika terdapat nilai pengamatan dan ramalan untuk n periode waktu, akan terdapat $n$ buah galat dan ukuran statistik standar berikut (Makridakis et all, 1999) yang dapat didefinisikan:

Nilai tengah galat (mean error)

$$
M E=\frac{1}{n} \sum_{i=1}^{n} e_{i}
$$

Nilai tengah galat absolut (mean absolute error)

$$
M A E=\frac{1}{n} \sum_{i=1}^{n}\left|e_{i}\right|
$$

Jumlah kuadrat galat (sum of squared error)

$$
S S E=\sum_{I=1}^{n} e_{i}^{2}
$$

Nilai tengah galat kuadrat (mean squared error)

$$
M S E=\frac{1}{n} \sum_{I=1}^{n} e_{i}^{2}
$$

Deviasi standar galat (standard deviation of error)

$$
S D E=\sqrt{\sum_{I=1}^{n} e_{i}^{2} /(n-1)}
$$

Ada pula ukuran-ukuran ketepatan lain yang sering digunakan untuk mengetahui ketepatan suatu metode peramalan dalam memodelkan data deret waktu, yaitu nilai MAPE (Mean Absolute Percentage Error), MSD (MeanN Squared Deviation), MAD (Mean Absolute Deviation)

MAPE merupakan ukuran ketepan relatif yang digunakan untuk mengetahui persentase penyimpangan hasil peramalan, dengan persamaan sebagai berikut

$$
M A P E=\frac{1}{n} \sum_{i=1}^{n}\left|P E_{i}\right|
$$

Galat persentase (percentage error)

$$
P E_{t}=\left(\frac{X_{t}-F_{t}}{X_{t}}\right) \times 100 \%
$$

MAD menyatakan penyimpangan ramalan dalam unit yang sama pada data, dengan merataratakan nilai absolut error (penyimpangan) seluruh hasil peramalan. Nilai absolut berguna untuk menghindari nilai penyimpangan positif dan penyimpangan negatif saling meniadakan. Persamaannya adalah sebagai berikut: 


$$
M A D=\frac{\sum^{R} \cdot\left|r(t)-Y^{2}(t)\right|}{\omega}
$$

Cara lain untuk menghindari penyimpangan nilai positif dan penyimpangan negatif saling meniadakan adalah dengan mengkuadratkan nilai kesalahan tersebut. MSD merupakan ukuran penyimpangan ramalan dengan merata-ratakan kuadrat error (penyimpangan semua ramalan). Persamaannya adalah sebagai berikut:

$$
\operatorname{MSD}=(1 / n) \sum\left(Y_{(t)}-Y^{\prime}{ }_{(t)}\right)^{2}
$$

Tujuan optimalisasi statistik seringkali dilakukan untuk memilih suatu model agar nilai MSD minimal, tetapi ukuran ini mempunyai dua kelemahan. Pertama ukuran ini menunjukkan pencocokkan (fitting) suatu model terhadap data historis. Pencocokan seperti ini tidak selalu mengimplikasikan peramalan yang baik. Suatu model yang terlalu cocok (over fitting) dengan deret data berarti sama dengan memasukkan unsur random sebagai bagian proses bangkitan, adalah sama buruknya dengan dengan tidak berhasil mengenai pola non acak dalam data. Kekurangan kedua dalam MSD sebagai ukuran ketepatan model adalah berhubungan dengan kenyataan bahwa metode berbeda akan menggunakan prosedur yang berbeda pula dalam fase pencocokan.

Dalam fase peramalan penggunaan MSD dan MAD sebagai suatu ukuran ketepatan juga dapat menimbulkan masalah. Ukuran ini tidak memudahkan perbandingan antar deret berskala yang berbeda dan untuk selang waktu yang berlainan, karena MSD dan MAD merupakan ukuran absolut yang sangat tergantung pada skala dari data deret waktu. Lagi pula, interpretasi nilai MSD tidak bersifat intuitif, karena ukuran ini menyangkut pengkuadratan sederetan nilai.

Karena alasan tersebut dalam hubungan dengan keterbatasan MSD dan MAD sebagai ukuran ketepatan peramalan, maka dipakai ukuran alternatif sebagai salah satu indikasi ketepatan dalam peramalan, yaitu MAPE.

\section{HASIL DAN PEMBAHASAN}

Data yang digunakan dalam tulisan ini merupakan data volume penjualan bulanan baja lokfom tipe $0,5 \mathrm{~mm} / \mathrm{lembar}$ PT. Satriamandiri Citramulia selama empat tahun mulai bulan September 2006 sampai dengan September 2010 (Megasari, 2010).

Penjualan selama empat tahun (September 2006 sampai dengan September 2010) menunjukkan bahwa jumlah penjualan mengalami fluktuasi periodik dengan panjang konstan yang menunjukkan adanya unsur musiman dalam deret data. Disamping itu juga terdapat unsur trend dengan pengaruh siklus yang menyebabkan garis trend cukup berfluktuasi. Selain itu, terdapat kecenderungan kenaikan yang tampak pada bulan Juli. Oleh karena itu, perusahaan dapat mencoba untuk meningkatkan produksinya sekitar bulan tersebut agar permintaan pasar dapat terpenuhi dan perusahaan dapat tetap mendistribusikan hasil produksinya ke masyarakat. Jumlah penjualan terbanyak pada bulan Juli 2007 yaitu sebanyak 151. Data tersebut dapat disajikan dalam Tabel 1. Hasil plot data disajikan dalam Gambar 1: 
Tabel 1

Data Penjualan Baja Lokfom Tipe 0,5mm/lembar September 2006 - September 2010

\begin{tabular}{rrrrrrrrrrrrrr}
\hline \multicolumn{10}{c}{ Bulan } \\
\hline $\mathbf{2 0 0 6}$ & $\mathbf{1}$ & $\mathbf{2}$ & $\mathbf{3}$ & $\mathbf{4}$ & $\mathbf{5}$ & $\mathbf{6}$ & $\mathbf{7}$ & $\mathbf{8}$ & $\mathbf{9}$ & $\mathbf{1 0}$ & $\mathbf{1 1}$ & $\mathbf{1 2}$ \\
\hline $\mathbf{2 0 0 7}$ & 107 & - & - & & - & - & - & - & - & 108 & 104 & 97 & 101 \\
\hline $\mathbf{2 0 0 8}$ & 109 & 108 & 119 & 124 & 130 & 151 & 123 & 118 & 113 & 104 & 98 \\
\hline $\mathbf{2 0 0 9}$ & 102 & 103 & 106 & 114 & 122 & 127 & 147 & 129 & 124 & 110 & 103 & 100 \\
\hline $\mathbf{2 0 1 0}$ & 99 & 100 & 95 & 98 & 102 & 110 & 121 & 114 & 104 & - & - & - \\
\hline
\end{tabular}

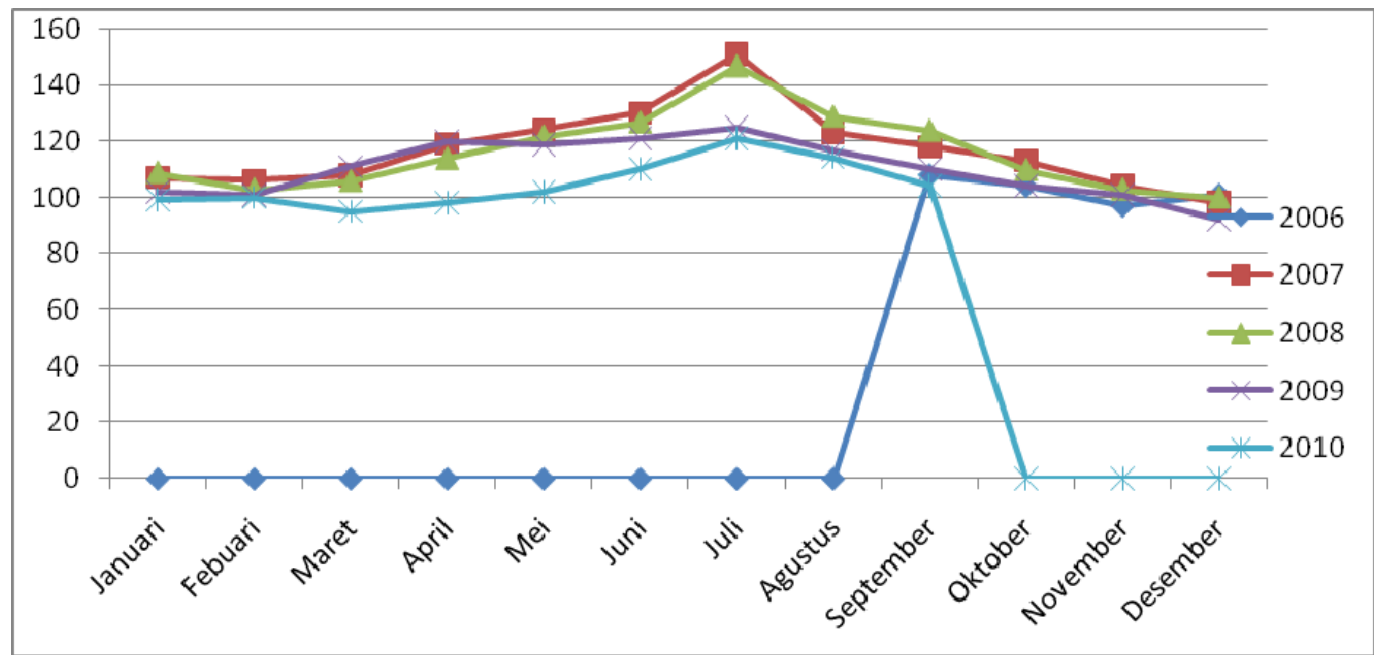

Gambar 1. Grafik penjualan.

\section{Hasil Peramalan}

Hasil peramalan data volume penjualan untuk ketiga metode peramalan (Moving Average, Exponential Smoothing dan Winters) dengan menggunakan empat periode dan nilai alpha $=0,1$, beta $=0,2$, dan gamma $=0,3$, dapat dilihat dalam lampiran. Untuk mendeteksi ketepatan dari hasil nilai ramalan yang dibandingkan dengan observasi (data actual) untuk ketiga metode peramalan data deret waktu (Moving Average, Exponential Smoothing, metode Winters) perlu ditentukan nilai MSE dan MAPE. Berikut ini adalah tabel perbandingan antara ukuran ketepatan peramalan MSE dan MAPE serta D-W untuk ketiga metode peramalan (Tabel 2):

Tabel 2

Perbandingan MSE, MAPE dan Durbin-Watson

\begin{tabular}{lrrr}
\hline \multirow{2}{*}{ Ukuran Ketepatan } & \multicolumn{3}{c}{ Metode Peramalan } \\
\cline { 2 - 4 } & Moving Average & Exponential Smoothing & Metode Winters \\
\hline MSE & 174,98 & 157,51 & 232,38 \\
MAPE & 9,518 & 8,841 & 11,028 \\
Durbin-Watson & 0,62894 & 0,559373 & 0,560042 \\
\hline
\end{tabular}


Tabel perbandingan MSE dan MAPE serta D-W di atas menunjukkan metode peramalan eksponential smoothing menghasilkan nilai MSE dan MAPE serta D-W yang minimum sehingga metode peramalan tersebut dianggap sebagai metode terbaik yang dapat digunakan untuk peramalan.

Untuk menelaah ketepatan dari model peramalan, dapat dibandingkan dengan data aktual yang ada. Untuk ini dapat digunakan data penjualan pada bulan Oktober 2010 sebesar 103 sebagai pembanding. Untuk periode tersebut (bulan Oktober 2010), hasil peramalan yang diperoleh dengan metode Moving Average, Exponential Smoothing dan metode Winters masing-masing sebesar 112, 107, dan 105. Jika ketiga nilai tersebut dibandingkan dengan data aktual sebesar 103, terlihat bahwa penyimpangannya 9 untuk Moving Average, 4 untuk Exponensial Smoothing dan 2 untuk Winters. Penyimpangan terkecil adalah dengan metode Winters, sehingga ada perbedaan sedikit dari hasil kajian dengan MSE dan MAPE. Namun, untuk hal ini tetap disimpulkan yang terbaik adalah metode dengan MSE dan MAPE terkecil, yaitu metode Exponential Smoothing.

Kajian Galat (Error) dapat dilakukan dengan mencermati penyimpangan data aktual dengan hasil ramalan yang dikenal dengan nilai galat perlu diperiksa apakah bersifat acak atau tidak, untuk ini dapat digunakan Statistik Durbin-Watson dengan rumus:

$$
D-W=\frac{\sum_{t=5}^{n}\left(e_{t}-e_{t-1}\right)^{2}}{\sum_{t=4}^{n} e_{t}^{2}}
$$

Hasil D-W untuk ketiga metode peramalan yang terdapat dalam Tabel 2 di atas perlu dikaji. Sebagai pembanding untuk mengkaji nilai D-W digunakan ketentuan sebagai berikut: dengan $n=49$, $k=1$ dan taraf nyata $5 \%$, diperoleh nilai $d_{L}=1.498$ dan $d_{U}=1.58$, serta $4-d_{U}=2.42$. Untuk ketiga metode peramalan yang digunakan nilai $\mathbf{D}-\mathbf{W}<\mathbf{d}_{\mathbf{U}}<\mathbf{4}-\mathbf{d}_{\mathbf{U}}$ maka dapat disimpulkan bahwa nilai galat tidak bersifat acak baik untuk metode Moving Average, Exponential Smoothing, maupun metode Winters.

\section{PENUTUP}

Berdasarkan hasil kajian dalam menentukan/memilih metode peramalan data deret waktu yang dianggap tepat untuk digunakan dalam peramalan volume penjualan PT Satriamandiri Citramulia dari tiga metode (Moving Average, Exponential Smoothing, dan metode Winters), dapat ditarik kesimpulan sebagai berikut: (1) dengan membandingkan nilai MSE dan MAPE untuk ketiga metode, yang nilainya paling kecil adalah exponensial smoothing sehingga disimpulkan bahwa peramalan dengan menggunakan metode eksponential smoothing dianggap yang terbaik dan dapat digunakan untuk melakukan peramalan volume penjualan PT Satriamandiri Citramulia; (2) dari kajian galat (penyimpangan) hasil peramalan untuk ketiga metode dengan statistik durbin Watson (D-W), dapat disimpulkan bahwa ketiga metode peramalan yang digunakan nilai D-W lebih kecil kriteria uji (D$\mathrm{W}<\mathrm{d}_{\mathrm{U}}<4-\mathrm{d}_{\mathrm{U}}$ ) sehingga dapat dianggap bahwa nilai galat tidak bersifat acak baik untuk metode Moving Average, Exponential Smoothing, maupun metode Winters; (3) untuk meyakinkan hasil ramalan perlu kajian terhadap hasil pengamatan apakah terdapat pencilan (outliers) atau tidak. Pencilan dari hasil pengamatan akan mempengaruhi fluktuasi data deret waktu dan dapat menurunkan tingkat ketepatan ramalan; (4) dalam melakukan peramalan data deret waktu secara cermat, nilai alpha dalam Exponential Smoothing, maupun kombinasi alpha, beta, dan gamma dalam metode Winters perlu ditentukan melalui metode coba-coba (trial and error) agar nilai ramalan yang dihasilkan lebih tepat; (5) tingkat kehomogenan data sangat mempengaruhi ukuran penyimpangan. Makin homogen 
data pengamatan, makin kecil nilai ukuran penyimpangannya dan dengan sendirinya tingkat ketepatan dari pendugaan/peramalan makin terandalkan.

\section{DAFTAR PUSTAKA}

Assauri, S. (1984). Teknik dan Metode Peramalan Penerapannya Dalam Ekonomi dan Dunia Usaha. Jakarta: Lembaga Penerbit Fakultas Ekonomi UI.

Bowerman, B. L. \& O'Connell, R.T. (1987). Time Series Forecasting. Boston: Duxbury Press.

Makridakis, S., Wheelright, S.C., \& McGee, V. E. (1999). Metode dan Aplikasi Peramalan, (U.S. Andriyanto dan A. Basith, terj.). Jakarta: Erlangga.

Megasari, Ries Tri. (2010). Perbandingan Antara Metode Moving Average, Exponential Smoothing dan Winters Dalam Peramalan Volume Penjualan PT Satriamandiri Citramulia Berbasiskan Komputer. Skripsi Strata 1 Program Studi Statistika FST Universitas Bina Nusantara, Jakarta. 